\title{
EL TRABAJO DEL DISEÑADOR DE INTERIORES EN EL PROCESO DE LA RESTAURACIÓN DEL PATRIMONIO ARQUITECTÓNICO
}

\section{INTERIOR DESIGNER'S WORK IN RESTORATION PROCESS OF ARCHITECTURAL HERITAGE}

\begin{abstract}
ALMA PINEDA ALMANZA
Arquitecta con Maestría en Restauración de Sitios y Monumentos. Doctorado en Artes, Universidad de Guanajuato. Departamento de Diseño. Calle Alfredo Pérez Bolde s/n. Marfil Guanajuato. Cp. 36046 Cuerpo académico Diseño y Artes. Línea de investigación Teoría y práctica en las artes y el diseño a.pinedaalmanza@ugto.mx.
\end{abstract}

\section{RESUMEN:}

La restauración de monumentos arquitectónicos requiere de especialistas en diversos campos; y en este proceso generalmente la dirección se le encomienda a los arquitectos. En las aulas de la Maestría de Restauración en la Universidad de Guanajuato (UG) se han integrado alumnos de diversas profesiones entre los que se encuentran los diseñadores de interiores. Uno de los errores que se han observado en la revisión curricular es que, por un lado, se permite que estos profesionales ingresen a la maestría, pero, por otro, la formación se centra en el arquitecto, en vez de que los especialistas desarrollen la restauración desde sus formaciones de origen. Este análisis expone actividades en las que el interiorista se integra al trabajo de restauración de monumentos y, por lo tanto, muestra la pertinencia de realizar un posgrado en esta área.

\section{PALABRAS CLAVE:}

Diseño de interiores, restauración de monumentos, interdisciplinariedad.

\section{ABSTRACT:}

The restoration of architectural monuments requires specialists in various fields, which usually contain with the addresses architects. In the classroom of the Master Restoration at the University of Guanajuato (UG), has been integrated students from different professions with them, we find the interior designers. One of the mistakes that have been observed in the curricular review, is that we invited all of these professional expertises, but we continue the training focuses on the architect, instead of try to develop restoration specialists from their formations of origin. This analysis activities that expose the interior designer integrates the work of restoration of monuments and therefore shows the relevance of performing a degree in this area.

\section{KEYWORDS:}

Interior design, restoration of monuments, interdisciplinary 


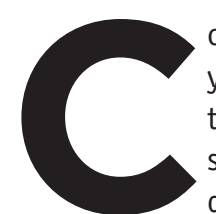
omo es bien sabido, la restauración de sitios y monumentos se ha planteado como una actividad multidisciplinaria, puesto que la conservación patrimonial arquitectónica depende de diversas áreas del conocimiento tanto en el proceso de planeación como en el de la ejecución.

El trabajo de restauración de monumentos presenta muchas coincidencias con la actividad que desarrolla el interiorista, por esta razón este ensayo comienza tratando de explicar las coincidencias y diferencias entre estos trabajos, para posteriormente centrarse en la actividad del diseñador de interiores $\mathrm{y}$, consecuentemente, en la necesidad de formar diseñadores de interiores en el campo de la Restauración de Monumentos que puedan participar en de las actividades de la conservación patrimonial de inmuebles.

\section{Diferencias y Coincidencias entre las activi- dades del restaurador de monumentos y el di- señador de interiores}

Dentro de las instituciones formadoras de restauradores la Universidad de Guanajuato ha tenido un papel muy destacado a nivel nacional e internacional con la Maestría en Restauración de Sitios y Monumentos ofrecida por el Departamento de Arquitectura de la División de Arquitectura, Arte y Diseño. Por mucho tiempo esta maestría se llamó Maestría en Arquitectura con la Especialidad en Restauración de Sitios y Monumentos, de tal forma que solamente los arquitectos que estudiaban esta maestría podían obtener el grado y se les denominaba Maestros en Arquitectura (M. en Arq.). Por otro lado, los estudiantes de esta maestría que eran de otras profesiones distintas a la arquitectura solo podían aspirar a ser Especialistas en restauración de sitios y monumentos. Con el tiempo se replanteó esta situación y se concluyó que todos los egresados deberían ser Maestros en Restauración de Sitios en Monumentos (MRSM), fueran arquitectos o no.

Por las aulas de la Maestría de Restauración han pasado principalmente arquitectos y en menor cantidad ingenieros civiles, historiadores, artistas visuales, químicos, diseñadores de interiores y arqueólogos, entre otros profesionales, todos ellos muy importantes en el proceso de la conservación. Sin embargo, este análisis se centrará en la imagen del diseñador de interiores; este profesional que en especial debería representar la perfección en el detalle arquitectónico del uso del espacio interior $y$, por lo tanto, muy importante en el proceso del reciclaje $\mathrm{e}^{1}$ o reutilización del edificio arquitectónico, acción fundamental en el proceso de restauración.

Debido al interés de estos profesionales de participar en el campo de la Restauración, se hace necesario hacer algu- nas observaciones que algunos de los alumnos de diseño de interiores deberán tomar en cuenta si deciden realizar estudios de posgrado. Partimos de que tanto el restaurador como el diseñador de interiores tienen la misma materia prima de trabajo. Esto es, es esencial que el trabajo se desarrolle sobre áreas construidas a las que debe adaptar los espacios útiles y be-llos, aunque esta cualidad de belleza no siempre es necesaria para el restaurador. Para el restaurador es fundamental dejar constancia de las intervenciones y dejar que el monumento continúe siendo un documento cuya historia debe ser verificable, la intervención será necesaria, aunque no siempre debe cumplir con el estándar de belleza; por ejemplo, un muro en ruinas donde se ejecutó a algún héroe, o eventos que no necesariamente se caracterizan por ser bellos pero sí por ser informativos e históricos.

Una de las diferencias encontradas entre el diseñador y el restaurador consiste en que, para el restaurador los espacios siempre serán históricos, mientras que para el diseñador de interiores estos son generalmente nuevos, al menos en el campo en que están acostumbrados hacer interiorismos en México, aunque igual pueden trabajar en espacios viejos, no necesariamente históricos, en Europa las circunstancias son diferentes, puesto que tienen que reutilizar los espacios históricos para volver a adecuarlos a nuevas funciones y en muchas ciudades estos espacios son muy solicitados por la escases de espacio, por la plusvalía que tienen los centros históricos europeos.

El primero, el arquitecto restaurador, puede intervenir desde las entrañas del edificio, (restructuraciones, consolidación, liberaciones, reintegraciones e integraciones); es decir, por su formación y experiencia en la construcción, deja el espacio en condiciones para ser útil, estructural y funcionalmente hablando, e incluso, a falta de especialistas en interiorismos, suele ser quien además debe diseñar su interior, mientras que el segundo generalmente, cuando interviene, se centra en la adecuación de espacios funcionales que ya están en condiciones de recibir un diseño interior, transformándolos en bellos y armoniosos. El interiorista puede sugerir integraciones, reintegraciones, liberaciones de elementos para lograr el buen funcionamiento de los inmuebles.

Hasta el momento se han mencionado algunos términos que diversos teóricos de la restauración han clasificado; para este efecto se ha recuperado el marco conceptual de las definiciones que han desarrollado de Salvador Díaz Berrío y Olga Orive para usarlo en nuestro estudio comparativo.

Existen ciertos términos que no son permitidos, en la restauración, pero que en el diseño interior son más usuales, como el término remodelación ${ }^{2}$, misma que entendemos como:

2 Reformar algo, modificando alguno de sus elementos, o variando su estructura. En Micro- 
ARTE \& DISEÑO, ISSN: 1692-8555, Vol. 12 N 1, Enero - Junio 2014 El trabajo del diseñador de interiores en el proceso de la restauración del patrimonio arquitectónico, págs.55- 61

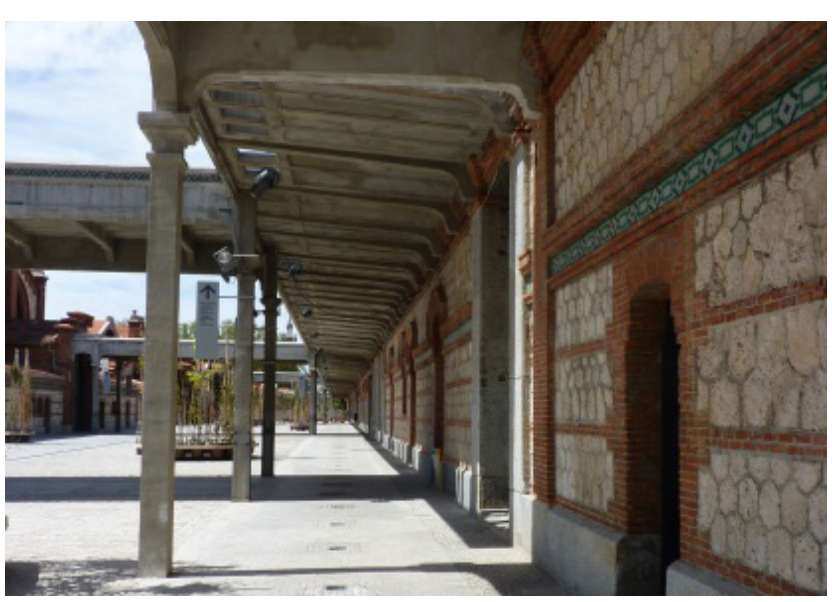

Imagen 1, Centro cultural Matadero, en Madrid. Reciclaje de lo que en un tiempo fue un rastro municipal de animales de Madrid.

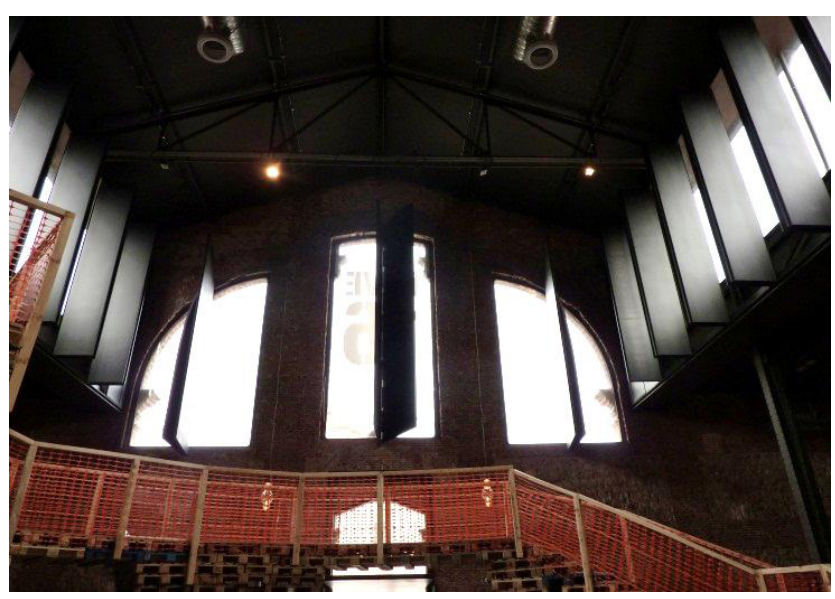

Imagen 2. Las grandes naves del antiguo rastro han sido adaptadas para espacios culturales de exposición y talleres en Matadero (Mardrid).

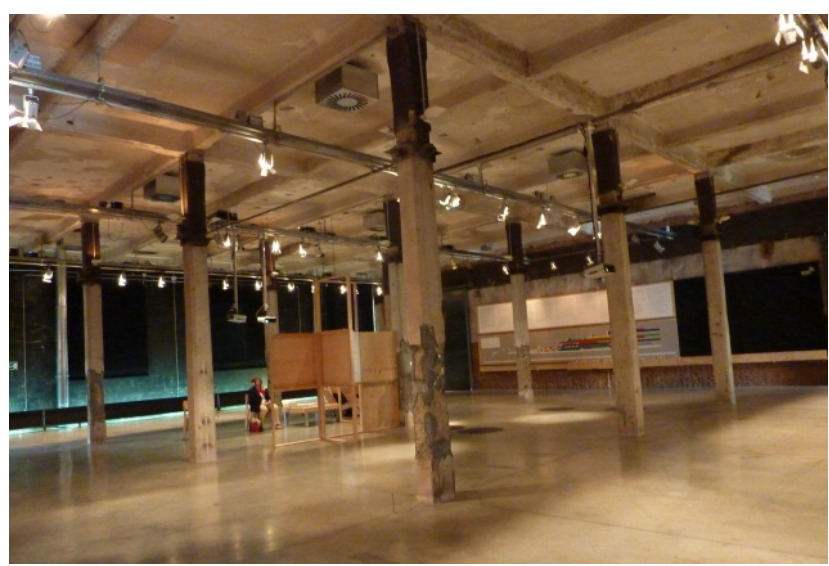

Imagen 3. Sala de exposición y experimentación para la expresión artística en Matadero (Madrid).

\begin{abstract}
“... el cambiar, el dar una nueva forma o volumen envolvente, manejamos un término aplicable a lo superficial y escultórico, pero insuficiente o incompleto para lo arquitectónico o urbano que contiene elementos esenciales mas allá de la forma o volumen envolvente."(Díaz Berrio, 1974)
\end{abstract}

La acción de volver a modelar, o cambiar de forma según la moda, situación que no permite la restauración, sino todo lo contrario, ya que una finalidad de la restauración es la conservación (Díaz Berrío, 1974). En cambio, el diseño interior, aunque muchos de sus fundamentos teóricos tienen como soporte la arquitectura, no es considerado como un arte, puesto que tiene esta posibilidad del cambio según modas y tendencias en un mismo edificio y por periodos que podríamos considerar "cortos". Observamos que la moda, la vanguardia y el estilo son materia fundamental en el trabajo del diseñador de interiores.

El término integración puede ser igualmente utilizado tanto por el restaurador como por el diseñador de interiores en su obra arquitectónica. Entendemos, entonces, por integración la "aportación de elementos claramente nuevos y visibles para asegurar la conservación del objeto" (Díaz Berrío, 1974); en este término caben acciones como la colocación nueva de acabados (según el estudio de caso, si es relevante o no se puede considerar conservarlo o liberarlo), iluminación, color, mobiliario, accesorios e instalaciones especiales, actividades que sin lugar a dudas corresponden también a un diseñador de interiores.

En el formato de edificio histórico deberán tener ciertas especificaciones que contemplará el restaurador. Los edificios antiguos nos ofrecen una gama muy interesante en todos estos factores que el diseñador de interiores puede aprovechar para su beneficio con su formación de origen, y será necesario que conozca las teorías de la conservación para intervenir los espacios. Rescatar lo original y conservarlo, restaurarlo si es el caso y enlazarse con los restauradores de bienes muebles en el proceso.

Salvador Díaz Berrío 1974 utiliza otro término que se refiere a la adaptación, adecuación y acondicionamiento; menciona que estos "no llevan implícita la componente de "anima" o "vida" que trasciende a lo meramente físico y utilitario y es componente esencial de los Bienes Culturales" (Díaz Berrío, 1974). Todos estos términos son perfectamente utilizados para el caso de darle un nuevo uso, una nueva ánima, al edificio. En algunos edificios históricos, la postura de integración de los diseñadores de interiores resulta interesante, puesto que se manifiesta por contraste, dejando muy claro la aportación contemporánea del edificio histórico; asunto que para algunos restauradores de la vieja guardia no es lo correcto, por su postura sumamente conservadora; en estos casos es necesario apegarse a los criterios estipulados por acuerdos in- 
ARTE \& DISEÑO, ISSN: 1692-8555, Vol. 12 Núm. 1, Enero - Junio 2014

ALMA PINEDA ALMANZA

ternacionales. ICOMOS se encarga de revisar las problemáticas que van surgiendo con respecto al Patrimonio Monumental emitiendo "cartas" disponibles en su página web.

\section{La actividad del diseñador de interiores}

El diseñador de interiores tiene dentro de sus actividades específicas de trabajo las referentes a la modificación de los espacios interiores, aunque, como se ha podido observar en la formación de diseñadores de interiores de la Universidad de Guanajuato, igualmente sus conocimientos se extienden a diversas especializaciones; incluso algunas no son precisamente "interiores", como el paisajismo, que se encarga del diseño de jardines y áreas verdes en general.

El diseño de interiores consiste en la planificación, distribución y el diseño de los espacios interiores de los edificios. Estos escenarios fisicos satisfacen las necesidades básicas de cobijo y protección, creando un marco e influyen en la forma de llevar a cabo las actividades, alimentan las aspiraciones de los ocupantes y expresan las ideas que acompañan sus acciones, afectan los puntos de vista, los estados de ánimo y la personalidad. En este sentido, los objetivos del diseño de interiores son el logro de ventajas funcionales, el enriquecimiento estético y la mejora psicológica de dichos espacios interiores. (Ching., 2011, p,36.)

Esta definición nos acerca hacia algunas de las actividades específicas del interiorista en las que destaca la planificación de esos espacios y la obtención de los espacios funcionales; la parte estética es muy interesante, pues en este apartado el interiorista suele manejar ciertas materias que no maneja el arquitecto, como el manejo específico del mobiliario, los accesorios, entre otras. Graeme Brooker y Sally Stone, (2011) definen el Diseño interior en los siguientes términos:

El diseño de interiores es una disciplina única que se diferencia de cualquier otro tipo de diseño. En primer lugar, hay que subrayar que todo interior está vinculado a la ubicación del espacio en el que se halla, y éste, a su vez, a un determinado contexto exterior. Para un proyecto de diseño de interiores es fundamental analizar bien estos condicionantes, ya que tienen tal repercusión en el diseño final que a menudo superan cualquier otra consideración ( $p .8)$.

Llama la atención que en esta definición centra la importancia del interiorismo en los contextos y de sus condicionantes. Se debe observar que las aportaciones a una teoría del Diseño Interior están basadas en las teorías de la arquitectura que están más desarrolladas. La realidad es que sí existen diferencias

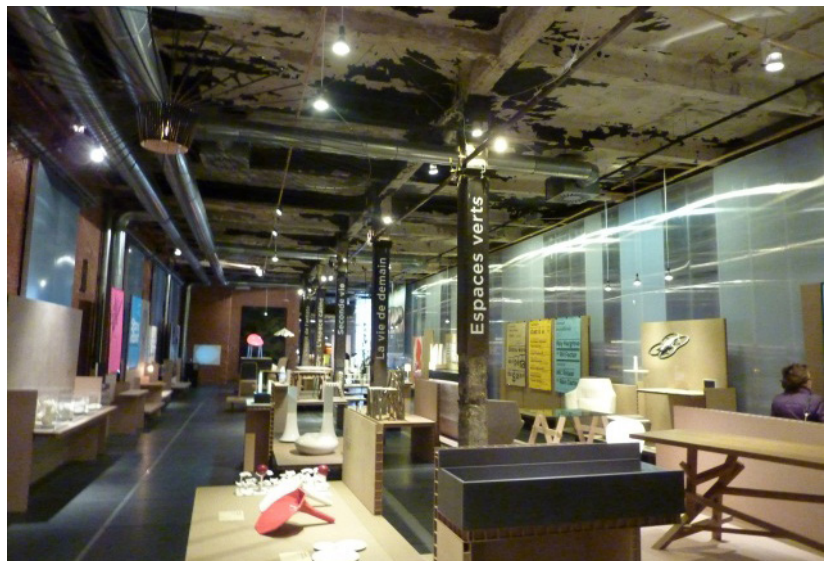

Imagen 4. Exposición temporal "el Diseño Francés". Ambas imágenes pertenecen al conjunto de Matadero, donde se trató de conservar los acabados originales y se integra todo un proyecto de iluminación museográfico

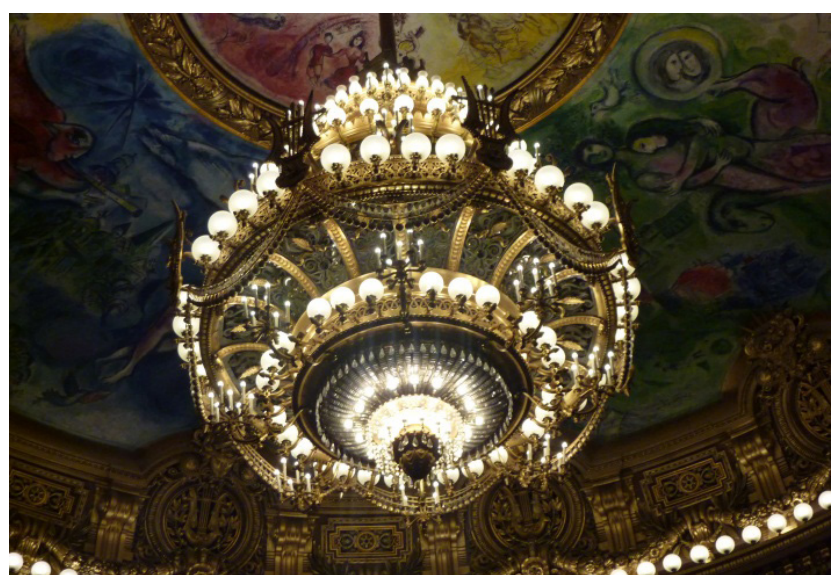

Imagen 5. Interior de la Sala de la Opera Garnier en Paris. Se puede observar pintura, estucados, maderas, luminarias, todo del espacio interior.

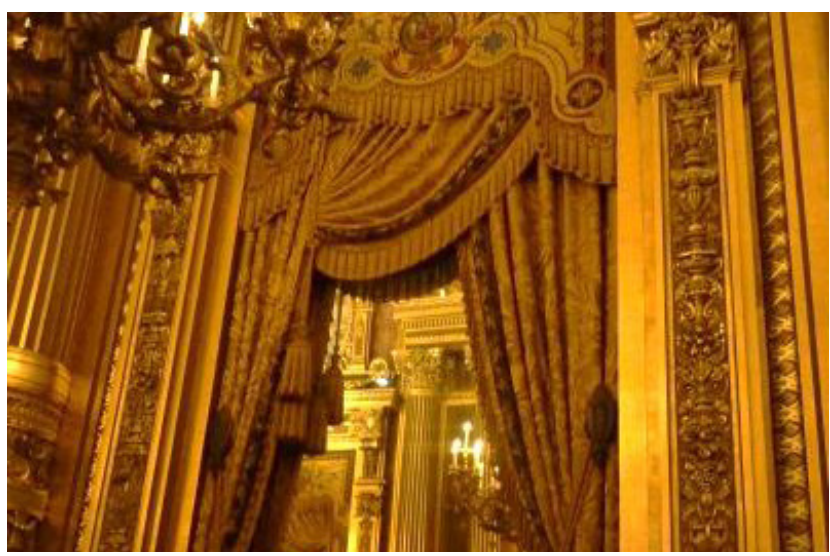

Imagen 6. Sala de fumadores en el edificio de la Opera Garnier. Los detalles de interiorismo requieren de un especialista en restauración, que conozca de telas, candiles, estucados y en general de procedimientos de conservación y de museografía. 
ARTE \& DISEÑO, ISSN: 1692-8555, Vol. 12 N 1, Enero - Junio 2014 El trabajo del diseñador de interiores en el proceso de la restauración del patrimonio arquitectónico, págs.55- 61

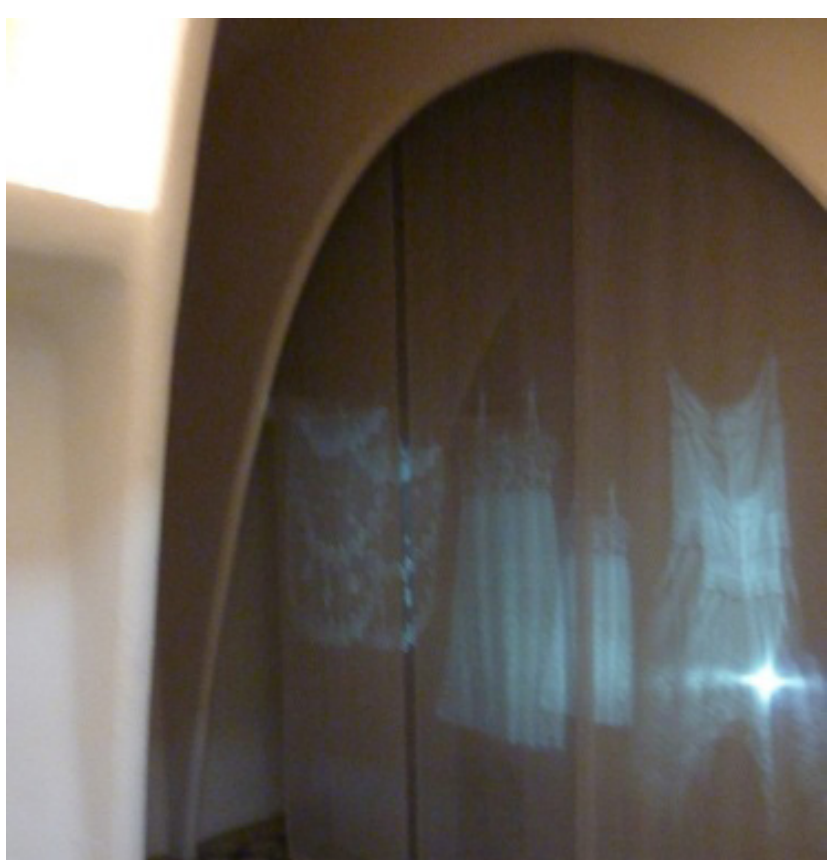

Imagen 7. La casa Batlló de Gaudí en Barcelona actualmente es un museo, al que se le han adaptado algunas reconstrucciones digitales para recrear la vida cotidiana.

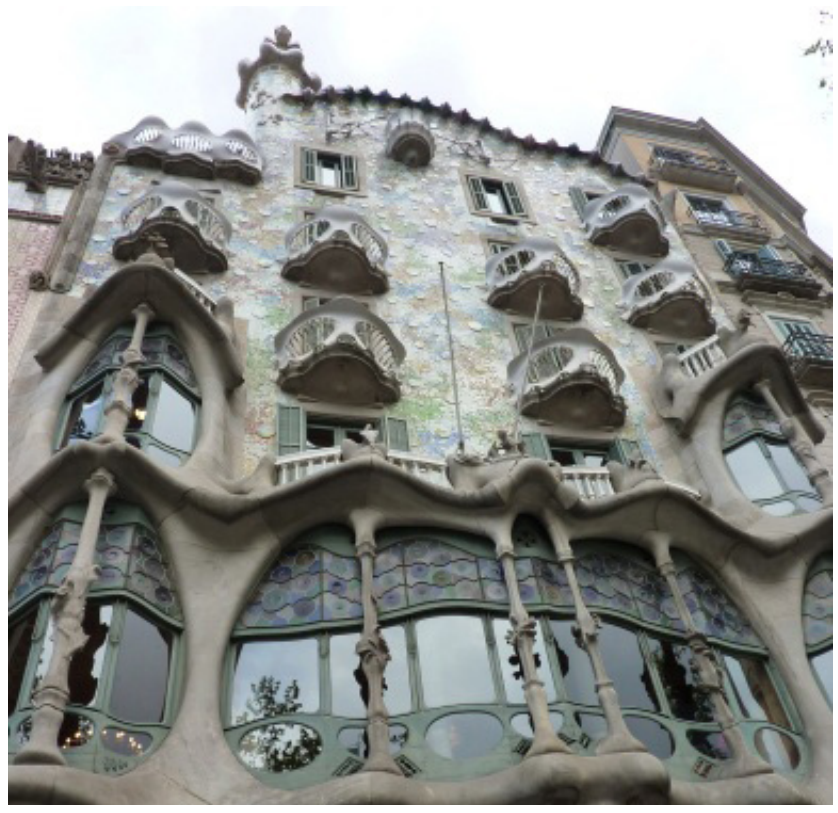

Imagen 8. Fachada de la casa Batlló; reconstruye la historia del inmueble y su función cotidiana. entre querer trabajar un diseño arquitectónico a un diseño interior; hemos planteado ya las bases, pero creemos necesario marcar también las actividades y especialidades sobre las que se puede desarrollar. A lo largo de este artículo se ha trabajado aportando una definición que parece más pertinente, que las anteriores por los elementos que involucra:

El diseño de interiores es la disciplina que parte de la arquitectura y que se encarga de la planificación de los espacios arquitectónicos construidos que requieren ser ambientados para un uso específico, donde la participación de diversos técnicos deben materializar los proyectos de función, acabados, iluminación, color, mobiliario y accesorios y revisar que todos estos espacios se encuentra envueltos en un confort térmico, acústico y olfativo, mas conveniente para las actividades que ahí se desarrollen; todo esto en un marco en el que se distingue una propuesta estética contemporánea que se basa en las tendencias del momento histórico y que además logre identificar a su dueño con los usuarios del espacio comunicando, además un mensaje de bienestar y confort a la sociedad a la que pertenece.

Esta definición trata de abarcar el argumento del espacio construido y cada una de las áreas que debe solucionar el interiorista, esto es además lo referente al símbolo. Así como la arquitectura es símbolo, el diseño interior lo tiene como parte de su identidad y de su forma de expresión.

Durante la formación del diseñador de interiores se tiene mucho cuidado en que desarrollen ciertas actividades que son fundamentales, como la planeación y organización funcional del espacio, esta es la base de la organización; la forma y el estilo tienen un papel igualmente importantes, pues a partir de esta parte se pueden definir los proyectos de acabados, iluminación, color, mobiliario y accesorios. De la función dependerán también el tipo de mobiliario, la calidad y cantidad de iluminación, el color más adecuado, el tipo de sonido, temperatura y de olores que se pueden filtrar al interior.

El uso específico del espacio definirá función y forma interna, y de ahí el resto de los elementos que hemos mencionado se derivarán como parte de este diseño interior. Ahora discutamos de las áreas de trabajo del interiorista.

Puesto que los espacios vacíos son la materia prima de este trabajo de diseño interior, se recalca que el interiorista debe tener mucho cuidado en el análisis interior de cada actividad, de cada detalle propuesto para la realización de cada función, y por ello que se estima que existen muchos espacios que necesitan de un especialista interiorista, que maneje la función, iluminación, color, mobiliario y accesorios, entre otras actividades que ya se han explicado. Así, definimos que las especialidades en las que el trabajo del interiorista es importante y tiene un desarrollo real y útil son además de las otras actividades compatibles como diseño residencial y administrativo, las concernientes con Paisajismo, Museografía, Escaparatismo, Escenografía y Restauración de Monumentos, por mencionar algunos campos del diseñador de interiores. 
La idea de llegar a este punto es enfocar que las bases de formación del conocimiento del diseñador de interiores son necesarias para estudiar, comprender e involucrarse en alguna especialización que se estudia a través de una maestría como Restauración de Monumentos. Así, el diseñador de interiores se convierte en un excelente candidato para ser colaborador en la conservación del patrimonio monumental.

\section{El Diseñador de interiores y la restauración de monumentos}

El diseñador de interiores está preparado en asuntos en los que el arquitecto no lo está, por ejemplo, en lo referente al conocimiento de los muebles y las líneas de diseño históricas y actuales, vincula los muebles y accesorios con la vida cotidiana y la historia, sus estilos y tendencias del momento, conoce el diseño de iluminación, resaltando los puntos de interés e ilumina de forma general el resto del espacio, aprovecha la luz natural, pero también sabe seleccionar qué elementos elegir, ya que sabe qué luz pude dañar algunos de los elementos que componen el contexto arquitectónico histórico. Los conocimientos de museografía, sus intervenciones, son los más adecuados, ya que mediante el estudio de investigación y análisis puede sugerir los accesorios necesarios, como tapetes, cortinas, espejos, etc. También deben ser analizados a la luz de la historia y de las vanguardias del momento.

El interiorista debe revisar todos los detalles de composición espacial. Ahora bien, si eso se traslada al estudio de la vida cotidiana a través de la historia, del conocimiento de la historia de los muebles, y del tratamiento adecuado en la conservación de pinturas, aplanados, molduras estucados, plafones, entre muchas otras cosas que conforman el interior de un monumento histórico, y si además conoce de las técnicas de restauración, consolidación e integración, su campo puede extenderse a actividades como consolidar aplanados, recuperar formas y colores, señalar los espacios de circulación, y mediar las condicionantes de los espacios en referente a las temperaturas ideales de conservación y el aislamiento de sonido y olores. Con estas reflexiones se puede observar la dimensión de los aportes en los trabajos de restauración, conservación y reciclaje, así como la toma de decisiones de un interiorista en el proceso de restauración es verdaderamente importante.

Esta sería una forma de analizar el trabajo del interiorista a través de la conservación del patrimonio, sin embargo, existen además aportaciones como lo referente a las integraciones, que comentarios en el primer apartado de este ensayo. Las aportaciones totalmente nuevas en un edificio, pero considerando la antigüedad del mismo, considerando bases teóricas de la restauración y bases de museografía aplicadas a los monumentos históricos, son materia de cada día en ciudades históricas europeas, que al mismo tiempo respectan el patrimonio, pero se conservan a la moda del diseño interior; aquí

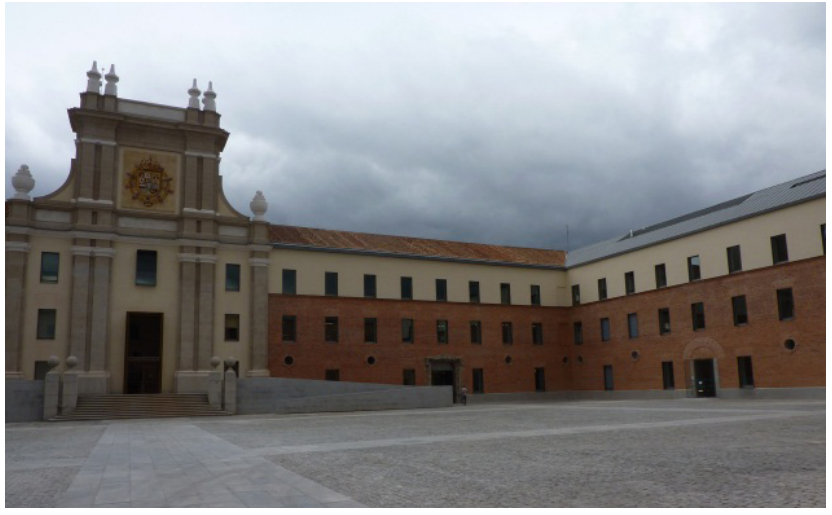

Imagen 9. El Palacio de Conde Duque se ha convertido en un centro cultural en Madrid.

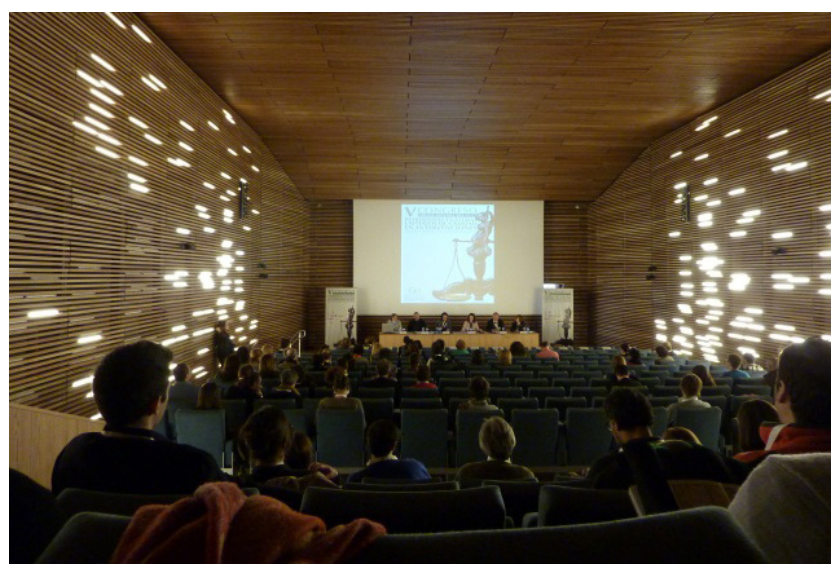

Imagen 10. Dentro del Palacio de Conde Duque se han instalado salas de conferencias totalmente modernas, se ha respetado la estructura original y se ha sobrepuesto el diseño interior.

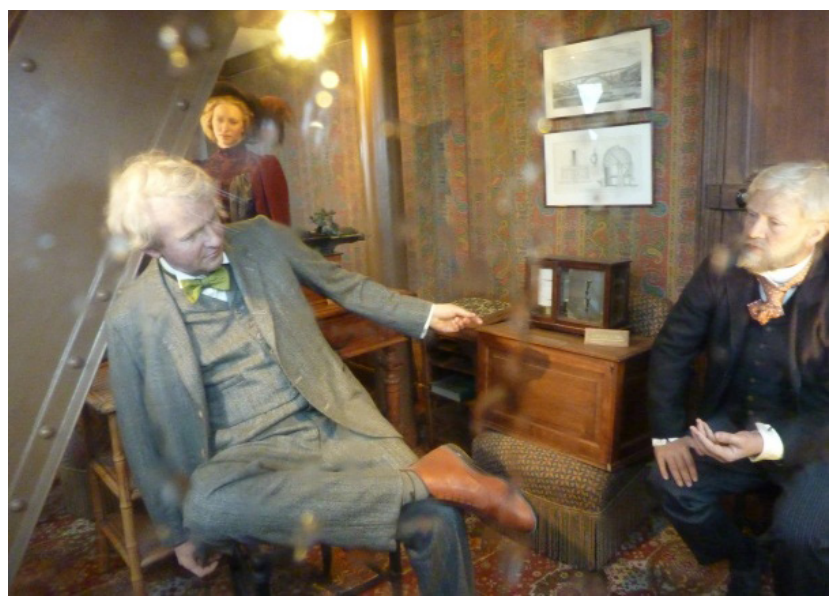

Imagen 11. Encontramos una recreación de la época con mobiliario, tapices, acabados y detalles, donde se observa al ingeniero Eiffel con el inventor Graham Bell. Estas recreaciones deben ser cuidadosamente elegidas por los conocedores de interiorismo. 
ARTE \& DISEÑO, ISSN: 1692-8555, Vol. 12 N 1, Enero - Junio 2014 El trabajo del diseñador de interiores en el proceso de la restauración del patrimonio arquitectónico, págs.55- 61

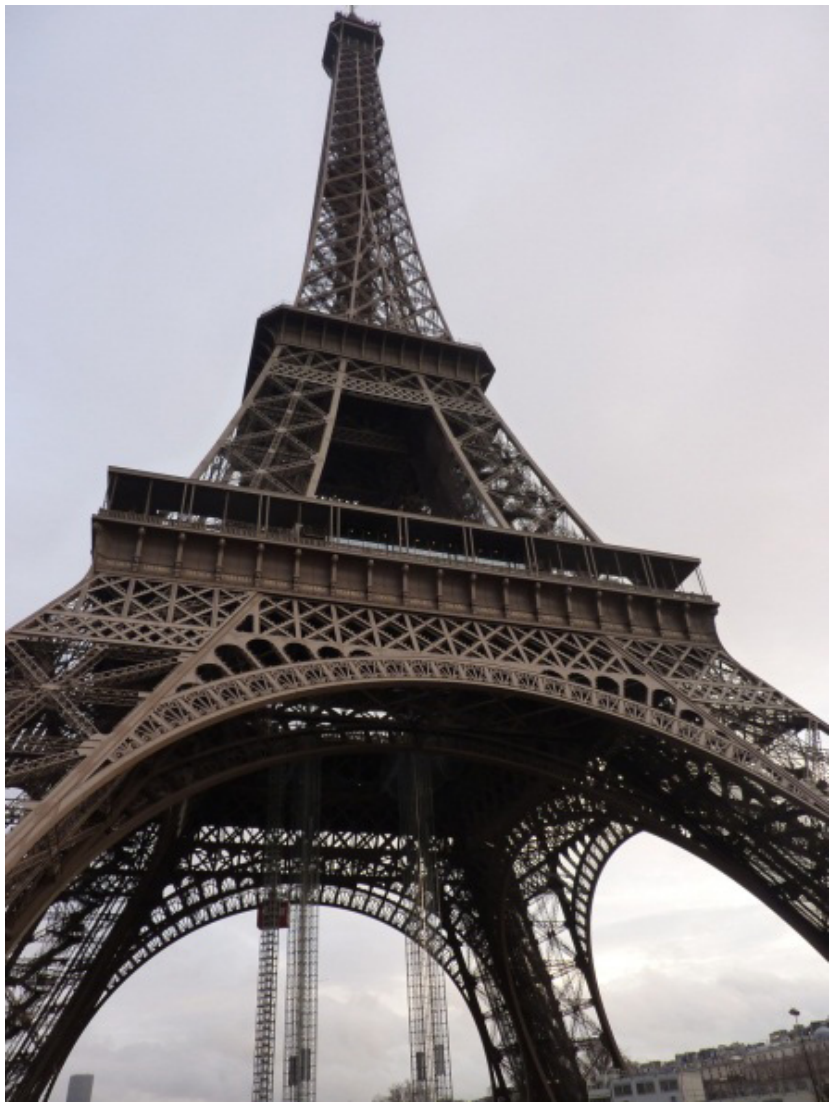

Imagen 12. En el último nivel de la Torre Eiffel se encuentra una cabina donde originalmente estaba el estudio del Ingeniero Eiffel.

el trabajo del interiorista se encuentra bien valorado, mientras que en México todavía no se termina de experimentar con esta propuesta.

Un espacio histórico nos ofrece cualidades espaciales, de altura, amplitud, de luz, color, materiales y acabados que pocas veces podemos encontrar en un diseño totalmente nuevo; pensamos que aprovechar todos estos recursos y volver a darle vida a un edificio histórico sin uso puede ser un campo muy rico para el diseñador de interiores.

Si el diseñador de interiores desea experimentar el trabajo de Restauración de Monumentos, seguramente que con la preparación que tiene y con los estudios de necesarios en conservación, sus propuestas serán de mucha utilidad en el proceso del proyecto, y por lo tanto, en la propuesta de integración y reciclaje estará garantizado.

\section{CONCLUSIÓN}

El trabajo del diseñador de interiores está subvalorado en México, pero es el momento para despuntar y aprovechar las oportunidades que ofrecen las diversas especialidades como la restauración, la museografía, el paisajismo, entre otras.

El diseñador de interiores necesita integrarse en los diversos campos de trabajo donde solo el arquitecto se había desempeñado, pero debe quedar claro que si bien las actividades que realizan tanto los arquitectos como los diseñadores de interio-res son diferentes, este último no lo ha demostrado como es debido; probablemente porque no se le ha dado la oportunidad; sin embargo, el momento de la multidisciplinariedad es ahora, y por lo pronto la Universidad de Guanajuato realiza un trabajo de investigación especializado con los diseñadores de interiores egresados de la Maestría de Restauración de Sitios y Monumentos para lograr estos proyectos más completos, de detalle y profesionales.

\section{REFERENCIAS BIBLIOGRÁFICAS}

Brooker, G. \& Stone, S. (2011). Diseño de interiores: manual para los futuros profesionales del sector. Barcelona: Océano.

Ching, F. D.K. \& Binggeli, C. (2011), Diseño de Interiores: manual. Barcelona: GG.

Díaz Berrio, S. Oribe B. 0. (1974). Terminología general en materia de Conservación del patrimonio cultural prehispánico. Presentado como ponencia en el XLI Congreso Internacional de Americanistas. México D.F.

DICCIONARIO Encarta Microsoft ${ }^{\circledR}$ Encarta $^{\circledR}$ 2007. ${ }^{\odot}$ 1993-2006 Microsoft Corporation.

Sire, M-A. ( 1996). La France du Patrimoine. Les choix de la Memorie. France: Gallimard.

Ferguson, R. (1998) (Ed.). A fin de siglo cien años de arquitectura. México. El Colegio de San Ildefonso, CONACULTA.

\section{FOTOGRAFÍA}

Alma Pineda Almanza, España 2012 y Francia 2013.

\section{FORMA DE CITAR ESTE ARTÍCULO}

Pineda Almanza, A. (2014). El trabajo del diseñador de interiores en el proceso de la restauración del patrimonio arquitectónico. Revista Arte y Diseño Facultad de Arquitectura, Arte y Diseño, Universidad Autónoma del Caribe, Barranquilla. ISSN 1692- 8555 Vol. $12\left(N^{\circ} .1\right)$. PP. $55-61$ 